\title{
Programmes for Uncontrolled donation after Circulatory Death: Clinical, Ethical and Legal Benchmarks
}

\section{Ivan Ortega-Deballon ${ }^{1,2,3 *}$}

${ }^{1}$ Emergency Medical Services Madrid, Spain

${ }^{2}$ McGill University Research Institute and Centre de Prélèvement d'Organes, Hôpital du Sacré-Coeur, Montreal, Canada

${ }^{3}$ Facultad de Medicina y Ciencias de la Salud. Universidad de Acala de Henares, Madrid, Spain

\section{Introduction}

Donation after circulatory determination of death (DCDD) is a form of organ donation that takes place after the cessation of circulatory function. Protocols for uncontrolled donation after cardiac death, in which candidates has suffered an unexpected or sudden cardiac arrest, have generated both promise and concern. On one hand, these protocols potentially increase organ donation rates by making potential donors certain individuals who suffer an out-of-hospital cardiac arrest (OHCA). On the other hand, they raise a number of ethical concerns regarding on several points that has been identified by scholars and emergency health care providers: [1] lack of truthfulness and transparency on the information approach to the next of kin of potential donors, and [2] the possibility that organ donation could compromise treatment delivered to, at least, some patients profile. According to the best and updated evidence knowledge available on resuscitation techniques and options of care, high-quality ongoing resuscitation could be provided before to judge as futile the resuscitation attempts.

In this article, the strengths and clinical, legal and ethical challenges of these protocols are discussed. By elucidating ethical concerns with existing protocols, it is the goal to affect positive policy change in the current ones and others that will likely be developed worldwide.

The donation and transplantation of organs and tissues retrieved from donors after circulatory death [1], following unexpected cardiac arrest [2], started over half a century ago [3]. The technical difficulties posed by the preservation of these organs and tissues depends on the so called Warm Ischaemic Time (WIT), defined as the time when the patient suffers the cardiac arrest to the cannulation in the block of a just declared deceased individual and looking forward her organ preservation. The WIT has been set at 120 minutes, after which the organs are considered unsuitable for transplantation [4]. This explains that for years these deceased donors after cardiac or circulatory determination of death were dismissed in favour of deceased donors after brain determination of death.

The concern of many health professionals and academics is the following: Spain has been and continues to be a worldwide reference in programs for uncontrolled donation after circulatory determination of death (u DCDD), so called uncontrolled due to the WIT cannot be defined exactly because of the unexpected, and mostly not witnessed, cardiac arrest. These donors were classified as category II donors of the Maastricht classification. Since 1996, severalEMS in Spain have increased the rate of organ donation in the context of $\mathrm{u}$ DCDD. In practice, based on currently applicable protocols, an individual presenting with refractory OHCA is transferred with continuous thoracic compressions and ventilation with the sole aim of preserving the organs, not to reverse the cardiac arrest. The victim is no longer a patient but a potential donor. Transfer is made to a hospital with the capability of non-heart beating organ donation, rather than to the nearest hospital. Cases are selected by their age and previous health profile (exclusion criteria include age over 60 years, infection, endocrine or neoplastic diseases, drug consumption or pregnancy, between others) [5]. The potential donor is transferred either in a physician staffed ground ambulance or emergency helicopter in order to fit with the WIT. The family, if not at the scene of the OHCA, is located by the police. They are asked to go immediately to the hospital and there they receive notification of the death of their relative. Transplant coordinators then, ask them for authorization to the organ retrieval. At this time, the potential donor is already in the operating theatre and has been cannulated and connected to organ preservation, non-therapeutic, system awaiting the result of the interview with the family.

\section{Reducing The Gap Between Decreasing Solid Organs Availability and The Growing Recipients' Waiting Lists}

There is a growing demand for organ transplantation due to the increased life expectancy in developed countries [6]. However, a number of factors have resulted in a gradual decrease in the amount of brain death diagnoses in hospital intensive care units throughout Spain. On one hand, there has been a significant improvement in road safety, which has reduced morbi-mortality from road traffic accidents, especially among motorcyclists, due to the compulsory use of helmets. On the other hand, specialized units have been introduced for more effective, multidisciplinary handling of patients with traumatic brain injuries or acute cerebrovascular diseases [7].

Given these circumstances, and the resulting decrease in the rate of organ donation due to the lack of candidates, the Spanish National Transplant Organization (ONT) decided to introduce interdisciplinary programmes for organ donation after circulatory death (DCD). These programmes involved not only pre-hospital services (Emergency Medical Services, EMS), and hospital services (emergency departments, intensive care units, transplant coordination, operating theatres, laboratory services, anatomical pathology, administration services, etc.) but also the ONT itself and the public (potential organ donors and recipients and their families). These are all essential components which help to coordinate and shape programmes [4-15] which have achieved results which are similar [14], and in some cases better [15] in terms of long term survival of organ recipients with a high quality of life.

*Corresponding author: Ivan Ortega-Deballon, Associate Professor and PhD candidate. Facultad de Medicina y Ciencias de la Salud. Universidad de Acala de Henares, Madrid, Spain, Tel: 346075252 12; E-mail: iviortega@gmail.com

Received July 24, 2014; Accepted September 18, 2015; Published September 25, 2015

Citation: Ortega-Deballon I (2015) Programmes for Uncontrolled donation afte Circulatory Death: Clinical, Ethical and Legal Benchmarks. Health Care Current Reviews 3: 135. doi: 10.4172/2375-4273.1000135

Copyright: (c) 2015 Ortega-Deballon I. This is an open-access article distributed under the terms of the Creative Commons Attribution License, which permits unrestricted use, distribution, and reproduction in any medium, provided the original author and source are credited. 


\section{Procedure of The Udcdd Programme in The Out-Of- Hospital Setting}

Uncontrolled DCDD programmes involve patients who have suffered cardiopulmonary arrest; in Spain and France, mostly an OHCA in a non-hospital environment. Following attempted cardiopulmonary resuscitation (CPR) for a predetermined period, they are transferred to the hospital as potential donors. From this moment nothing more is done to save the life of the patient, only to preserve the organs. This situation corresponds to category II of the Maastricht classification, that is to say, they are termed uncontrolled donation as the exact WIT is not known because the event which triggered the OHCA was sudden and unexpected. The EMS team who is treating the patient must then activate the protocol [4].

\section{Ideal Management of Emergency Medical Services Resources With Currently Active Udcdd Program: Avoiding Ethical, Legal and Clinical Issues Currently Present}

In all of the $u$ DCDD programs currently active in Spain, is the EMS which put the resources at the disposal of a potential donor. This includes ever a physician staffed transportation with also a specialized emergency nurse and an emergency medical technician completing the crew. The transport is realized in a ground ambulance, or even in air ambulances (helicopters), if the distance to the nearest hospital will jeopardise the WIT [5].

Other international uDCDD programmes such as the one in New York City [15] have come up with a pioneering resolution to an interesting operational issue. Once a potential donor is identified, an organ preservation vehicle (OPV) carrying the specific staff and materials required for this process, travels to meet the local EMS unit who are attending the OHCA. The patient is no longer considered a victim, but as deceased. The death is certified in situ by the OPV medical team. It is only then that the OPV team begin the transfer. This facility is not part of the healthcare operation provided by EMS; it is an ad hoc vehicle to overcome the logistical and resources management dilemmas posed by u DDCD programmes. In this way, both the EMS vehicle and its crew are constantly available to deal with medical emergency situations.

However, in Spain [8-14] and France [10-16], the crew members (doctors, nurses, emergency medical technicians), the resources (advanced life support units, ground or air ambulances), and devices (automated chest compression devices) belong to the EMS. This calls for an analysis of $\mathrm{u}$ DCDD programmes from a management perspective, particularly with regards to the economic principle of opportunity costs, which is defined as the value of the next best alternative use when deciding whether to spend scarce resources for one purpose rather than another [17]. Under current u DCDD programmes in Spain and France, the potential donor is taken to the hospital by an advanced ground/air ambulance. The donor is no longer treated or considered a patient, as all resuscitation attempts have judged futile at that moment. The transfer of the potential donor is performed by a complete team of health care providers. This highly specialised, and scarce, resource is not available to attend other medical emergencies calls for a period of at least 120 minutes while the process is underway [4]. Can we afford such a high opportunity cost?

We should analyse all the consequences of such current protocols from a cost-effectiveness point of view. It must be taken into account that the individual, transferred by these scarce but necessary means, is not guaranteed to become finally a real donor, due to family refusal or a variety of medical or legal exemption factors. The last review of the Madrid (Spain) u DCDD programme showed that $44 \%$ of cases using this protocol did not result in any organ retrieval, for one reason or another [18]. In all of these cases, the specialised resources described above were used, which means that in all of these cases (100\%), important resources were withdrawn from their essential mission: providing treatment in potential and coincident accidents and emergencies.

Some of the reasons for not obtaining organs at the end of the process include:

1. Problems with the deceased donor candidate such as: medical contraindication, pathologies detected in his/her past medical history on arrival to the hospital, age exclusions in the protocol, or return of signs of circulation (sic).

2. External problems such as: refusal due to any exclusion criteria applied from the receptor hospital, refusal of family consent to organ retrieval from an individual who has already been cannulated in the operating theatre (sic), judicial refusal of the procedure, logistical errors (e.g: the donor cannot be correctly cannulated due to technical problems or cannulation and connection to an extra-corporeal circuit proves to be ineffective and both are withdrawn) and time wasting during the inhospital process (therefore exceeding the WIT) [2-4].

All of this has created unease within a part of the EMS professionals in Spain and France. They have claimed for changes in current protocols in accordance with the lex artis, the state of the art of emergency medicine and nursing care, as well as the effective, efficient and balanced management of EMS (not only technical but also human) resources [19-21]. The use of resources which are so limited and so specialized, and above all, dedicated to emergency medical purposes, causes the opportunity cost to be extremely high. Especially when managerial decisions can cause the neglect of the universal principle for the pursuit of professional excellence known as 'patients first' ethic principle [22-25].

\section{Concluding Remarks and Proposals}

All the health care providers are responsible for instilling confidence in patients and transparency face to their families. Therefore we put forward our opinion on the management of emergency resources which agrees with professional excellence. (Figure 1)

To be precise, we want to lay down the following managerial priorities:

1. All Advanced Life Support units (air or ground ambulances) should ensure the following care:

a. a. High quality ongoing CPR during the transport and transfer of patients selected by a predictive model, in order to be followed by an hyper invasive approach considering the trigger which provokes OHCA on arriving at the hospital (i.e: percutaneous coronary intervention in the cath-lab in arterial coronary disease, extracorporeal membrane oxygenation in refractory cardiogenic shock, thrombolysis if embolism is the origin of the OHCA, targeted temperature management, etc).

b. b. Only when Ongoing CPR has been unsuccessful $a b$ 


\section{Management options for victims of out-of-hospital cardiac arrest}

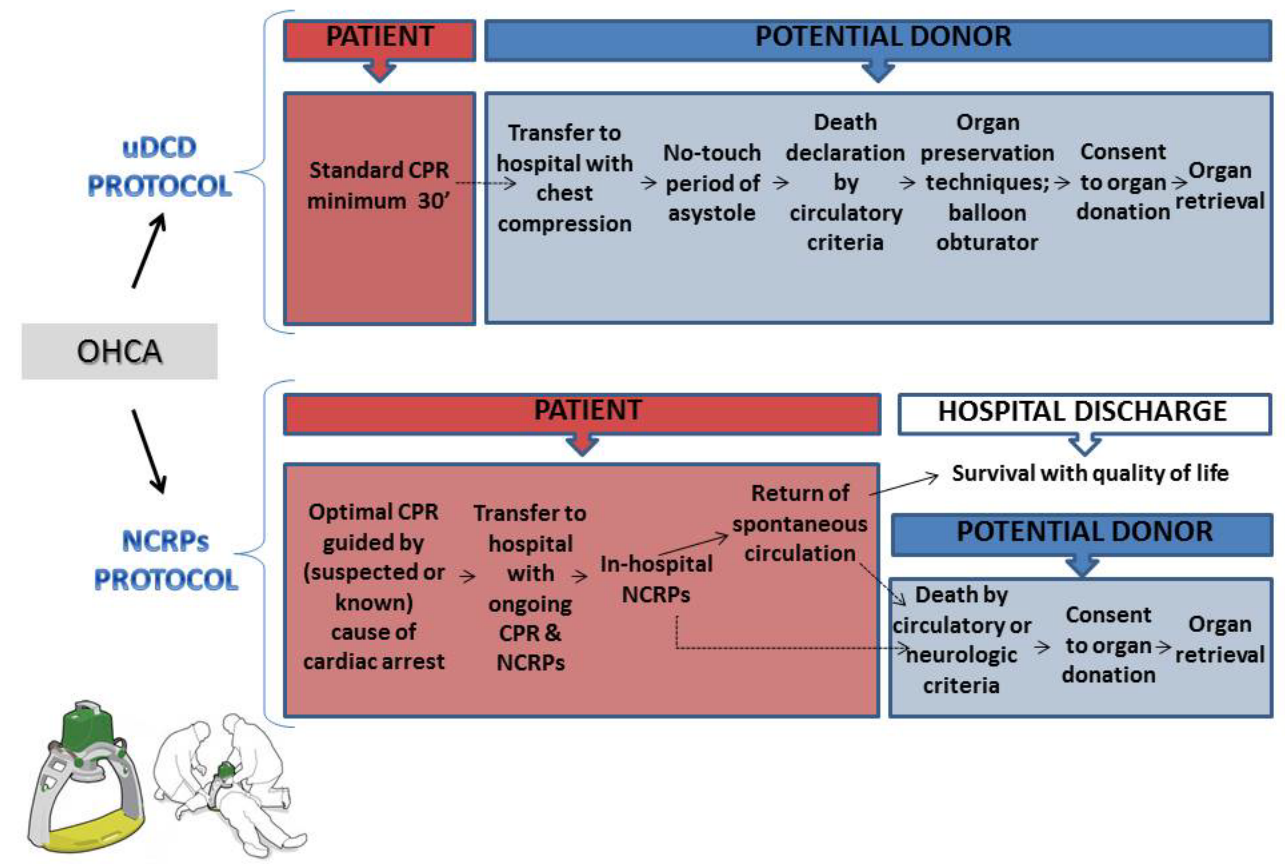

Figure 1:

initio, or judged futile for a specific patient or when hospital technology fails or is not deemed successful should the patient be considered as a potential donor. At this moment we can say that we offered to the patient all the possibilities and care that each one deserves.

2. A resource as scarce and specialized as an advanced life support, air or ground, ambulance is not the most practical option for carrying out the $\mathrm{u}$ DCDD program, in view of the ethic concept of distributive justice of resources. In regions where there is only one helicopter or ambulance, using them for this type of mission can infer a high opportunity cost resulting in conflicts. This could potentially give rise to legal repercussions including financial liability due to malfunctioning or misuse of public services. The New York u DCDD protocol has managed with this conflict by preparing an ad hoc vehicle (organ preservation unit) to respond to this kind of transportation.

3. The absolute priority of EMS should be to save lives. Involvement in u DCDD should only be an additional task after undertaking highly specialised ongoing CPR training. No region in Spain performs currently the first option proposed in the Figure 1 (Non-conventional resuscitation management: high quality ongoing CPR as a bridge to specific in-hospital techniques and treatments)., although very recently some pilot protocols are beginning right now due to the above mentioned conflict of interest that exists currently. However, seven regions carry out the second option (u DCDD protocols). We wonder, aligned with other authors [21-25], if we are looking forward to save the lives of patients with the same power that has been delivered to implement and develop u DCDD protocols.

We hope that policy makers, health professionals and the general public share these claims. Many countries wish to increase organ donation rates in an ethically, legally and clinically sound manner to reduce the gap between decreasing available vital organs for transplantation and the continuous growing waiting lists. An unexplored path to achieve this goal might be to implement a protocol for a comprehensive management of OHCA (Figure 1) already proposed elsewhere [21] and that includes two options: 'non-conventional resuscitation procedures option' in selected patients, underpinned in a predictive model focused on the reversible cause of OHCA (option 1) or a protocol for $\mathrm{u}$ DCDD (option 2) if the 'ongoing and high quality resuscitation option' is not indicated or considered as futile, obviously only after that conventional resuscitation attempts have been provided.

To implement such a protocol, require drawing a bridge that links the OHCA management from the prehospital setting to the hospital one. Therefore, a solid link is necessary between local EMS and inhospital emergency room and critical care units. The merge of both options, when based on transparency and on a prior open public debate including all the stakeholders, are a laudable and effective option that several countries may explore. The u DCDD programs have reported positive cost-effectiveness outcomes mostly in Spain and France in terms of long term functioning grafts. But we claim that essential modifications considering non-conventional resuscitation attempts for refractory OHCA must be urgently introduced in current $u$ DCDD programs.

Several health care systems worldwide have the necessary tools to implement such protocols. We are confident that the willingness to do this much better than now, does exist too.

\section{References}

1. del Río-Gallegos F, Escalante-Cobo JL, Núñez-Peña JR, Calvo-Manuel E (2009) [Donation after cardiac death: cardiac arrest during donor maintenance after brain death]. Med Intensiva 33: 327-335. 
Citation: Ortega-Deballon I (2015) Programmes for Uncontrolled donation after Circulatory Death: Clinical, Ethical and Legal Benchmarks. Health Care Current Reviews 3: 135. doi: 10.4172/2375-4273.1000135

2. Matesanz R (2008) El modelo español de coordinación de trasplantes. $2^{a}$ edición. Grupo Aula Médica SL. Madrid.

3. Gracia D (2001) [Organ transplantations: half a century of ethical pondering]. Nefrologia 21 Suppl 4: 13-29.

4. Mateos Rodríguez A (2010) Análisis de cuatro años de funcionamiento de un programa de donante a corazón parado extrahospitalario. Emergencias 22: 96-100.

5. Mateos A, Navalpotro JM, Ortega I, Moreno R, Barba C et al. (2011) Traslado en helicóptero de donantes tras muerte cardíaca. Emergencias 23: 372-374.

6. Matesanz R (1996) Documento de consenso español sobre extracción de órganos de donantes en asistolia. Nefrología. Vol.16.

7. Matesanz R(2010) Nuevas formas de morir y donación de órganos.

8. Sánchez-Fructuoso $\mathrm{Al}$, Marques $\mathrm{M}$, Prats $\mathrm{D}$, Conesa $\mathrm{J}$, Calvo $\mathrm{N}$, et al. (2006) Victims of cardiac arrest occurring outside the hospital: a source of transplantable kidneys. Ann Intern Med 145: 157-164.

9. Andres A, Dipalma T, Gad N (2010) Kidney Transplantation from donation after cardiac death donors who present irreversible cardiac arrest in the street or at home. Am J Transplant [Abstract]. 338-339.

10. Antoine C, Barrou B, Jacob L ( 2010) Uncontrolled NHBD program in France. Am J Transplant. 443.

11. Arranz AR (2007) DCD from the streets. Procedures and Quality Assessment. 2007 Organ Donation Congress. [Abstract]. Philadelphia, PA

12. Barrou B, Thibault $\mathrm{F}$, Ferhi $\mathrm{K}$ et al. Management of renal perfusion in uncontrolled non heart beating donors Comparison of in situ perfusion and normothermic ECMO. Am J Transplant [Abstract]. 2010; 10(suppl 4): 72.

13. Fieux F, Losser MR, Bourgeois E, Bonnet F, Marie O, et al. (2009) Kidney retrieval after sudden out of hospital refractory cardiac arrest: a cohort of uncontrolled non heart beating donors. Crit Care 13: R141.
14. Ribalta A, Gallardo J, Ruiz A, Deulofeu R.( 2009) Programa de donación a corazón parado de Cataluña. Med Clin Monogr (Barc).10:18-21.

15. Wall SP, Kaufman BJ, Gilbert AJ, Yushkov Y, Goldstein M, et al. (2011) Derivation of the uncontrolled donation after circulatory determination of death protocol for New York city. Am J Transplant 11: 1417-1426.

16. Agostinucci JM, Ruscev M, Galinski M, Gravelo S, Petrovic T, et al. (2011) Outof-hospital use of an automated chest compression device: facilitating access to extracorporeal life support or non-heart-beating organ procurement. Am J Emerg Med 29: 1169-1172.

17. Von Wieser $F$ (1914) Theorie der gesellschaftlichen Wirtschaft.

18. Andrés A (2011) Efectividad del programa de donación en asistolia. SUMMA 112 y SESCAM con el Hospital 12 de Octubre. Revisión de 2005 a 2009. Formación interna. Sesión SUMMA 112. Enero.

19. Ortega I (2002) Aspectos ético-legales en las emergencias extrahospitalarias Metas de Enfermería 5: 26-30.

20. Documentos y actas de las reuniones del Grupo de Trabajo de la Agence de la Biomédicine (ABM).

21. Rodríguez-Arias D, Deballon IO (2012) Protocols for uncontrolled donation after circulatory death. Lancet 379: 1275-1276.

22. Doig CJ, Zygun DA (2008) (Uncontrolled) donation after cardiac determination of death: a note of caution. J Law Med Ethics 36: 760-765, 610.

23. Bracco D, Noiseux N, Hemmerling TM (2007) The thin line between life and death. Intensive Care Med 33: 751-754.

24. Zeiler K, Furberg E, Tufveson G, Welin S (2008) The ethics of non-heartbeating donation: how new technology can change the ethical landscape. $J$ Med Ethics 34: 526-529.

25. Perkins GD, Brace S, Gates S (2010) Mechanical chest-compression devices: current and future roles. Curr Opin Crit Care 16: 203-210. 